\title{
Uso dos computadores nas escolas públicas do Alto Sertão da Paraíba
}

\author{
Adriana Damasceno $^{1}$, Amanda Diniz ${ }^{1}$, Mayrlla Lopes ${ }^{1}$, Renato Albuquerque ${ }^{1}$ \\ ${ }^{1}$ Centro de Ciencia e Tecnologia Agroalimentar - UFCG \\ Rua Jario Vieira Feitosa - 58.840-000 - Pombal - PB - Brazil \\ adrianacarla@ccta.ufcg.edu.br
}

\begin{abstract}
Computers are quite helpful in pedagogical activities. However, teachers do not use them frequently and few works focus on its causes. In this paper, we study computer usage by public schools teachers from in the Paraíba countryside. We describe the teachers' knowledge in computer technology, the infrastructure of public schools, and possible interactions between them.
\end{abstract}

Resumo. Os computadores são úteis como ferramentas pedagógicas. No entanto, estes não são usados com frequência e poucos estudos foram realizados para entender as causas. O propósito deste trabalho é estudar o uso dos computadores pelos professores de escolas públicas do Alto Sertão Paraibano, caracterizando o conhecimento e infra-estrutura a que eles são submetidos.

\section{Introdução}

Os computadores são grandes aliados no cotidiano escolar. Eles oferecem possibilidades pedagógicas e acesso a informações que não seriam possíveis sem o seu intermédio. No entanto, observa-se que estes não são usados em salas de aula de escolas públicas frequentemente [Costa and Almeida 2012].

Vários estudos foram realizados para identificação dos motivos deste desuso em diversas cidades [Silva and Carvalho 2011] [Jeske et al. 2009] [Andrade et al. 2012]. Observam-se alguns fatores tais com a falta de infraestrutura de informática disponível, treinamento dos professores a nível pedagógico e em softwares específicos, suporte técnico e cultura ambiental.

Alguns estudos na cidade de Pombal foram realizados para caracterizar o perfil dos alunos de escolas públicas na área de Informática [Damasceno et al. 2011]. No entanto, não foram identificados esforços para levantar o perfil de uso dos computadores pelos professores em sala de aula. Diante disso, faz-se necessário estabelecer o perfil do uso dos computadores em escolas públicas da Paraíba para posteriormente traçar planos de mitigação relativos ao uso dos computadores.

Para isso, realizou-se um survey cujo propósito foi estudar a relação entre o hábito do uso dos computadores pelos professores, a infraestrutura computacional de seus locais de trabalho e o uso dos computadores em salas de aula para professores de escolas públicas em 6 cidades do Sertão Paraibano. As variáveis indepentendes foram definidas como o hábito do uso dos computadores pelos professores e a infraestrutura computacional de seus locais de trabalho. A variável dependente foi definida como o uso dos computadores em salas de aula pelos professores. 
Aplicamos 134 questionários em 8 cidades do Alto Sertão paraibano para responder às seguintes questões: (1) Como os professores são avaliados em conhecimentos de informática? (2) Qual o nível da infraestrutura computacional disponível para os professores? (3) Como os professores usam os computadores durante suas aulas? (4) A infraestrutura disponível e o conhecimento em informática influenciam o uso dos computadores em sala de aula?

O objetivo desse artigo é caracterizar o uso dos computadores de uma parte das escolas públicas do Sertão Paraibano. A Seção 2 apresenta a fundamentação teórica e trabalhos similares. A Seção 3 detalha a metodologia usada para tratamento dos questionários. Na sequencia, a Seção 4 apresenta os resultados da caracterização do uso dos computadores nas escolas. Finalmente, a Seção 5 contém as conclusões deste trabalho.

\section{Referencial Teórico}

A inclusão digital não se resume a disponibilizar computadores para as pessoas, mas capacitá-las para a utilização eficaz dos recursos tecnológicos possíveis. No entanto, somente a aquisição dessas máquinas não é suficiente porque seu uso será relevante quando incorporado significativamente às práticas pedagógicas das escolas [Nascimento et al. 2011].

Algumas análises das condições efetivas de uso das salas de informática identificam que as dificuldades são de ordem física, retardos de cronogramas e problemas de instalações de hardware e software nos computadores, além de condições pessoais e profissionais de trabalho do professor [Costa and Almeida 2012]. Sendo assim, os professores são desafiados a atualizar seus conhecimentos iniciais e avaliar as mudanças necessárias para inovar suas práticas pedagógicas [Molin et al. 2012].

Para tanto, é necessário criar estratégias para que o professor reflita sobre a sua prática e sobre a sua importância nesse novo contexto educacional e social, definido dentro da sociedade da informação e do conhecimento. Nesse ambiente, professores e alunos podem tornar-se sujeitos ativos diante da quantidade de informações recebidas no dia-a-dia, uma vez que a legislação garante a formação global dos seres humanos [Santos et al. 2011].

O governo lançou o programa Projeto UCA (Um computador por Aluno) que possibilita a distribuição de laptops a professores de escolas públicas. Foram realizados estudos exploratórios que evidenciam as principais dificuldades no uso de computadores pelos professores na cidade de Araucária (PR) e no estado do Tocantins [Andrade et al. 2012, Gomes and Sá 2012]. Constatou-se que os seguintes fatores limitam o uso dos computadores: experiência pessoal com o uso da tecnologia, formação, suporte técnico e pedagógico no interior da escola e questões infraestruturais e da cultura da escola.

No entanto, a criação de estratégias de melhoria desse panorama depende da caracterização do uso dos computadores em escolas públicas. Vários trabalhos foram realizados para levantar o perfil de uso desses computadores. Nascimento et al [Nascimento et al. 2011] levantou algumas características principais de uso dos laboratórios de informática educativa na cidade de Fortaleza. Com isso, descobriu-se que $81 \%$ dos professores entrevistados relataram que não tinham um horário específico para planejamento de aulas no laboratório. 
Silva et al [Silva and Carvalho 2011] investiga os mecanismos de gestão e uso dos laboratórios de informática em duas escolas públicas de Recife. Eles realizaram entrevistas com os professores para avaliar a necessidade do computador. Ademais, observações feitas ao cotidiano da escola permitiram constatar que o uso do computador é importante para o aprendizado dos alunos durante as aulas. No entanto, não há o uso efetivo por falta de capacitação dos professores e limitação quanto à quantidade de computadores.

Odorico et al [Odorico et al. 2012] investigou o desuso de laboratórios de informática em duas escolas públicas. Foram aplicados questionários, de onde se pode constatar que a formação inicial do professor não tinha influência na adoção da informática no ensino. No entanto, constatou-se falta de planejamento no processo de uso dos computadores pelos professores, causando desmotivação. Em contrapartida, o estudo de caso realizado com professores de Matemática mostrou resultados positivos na adoção de recursos computacionais em sala de aula.

\section{Métodos}

Nosso objetivo foi identificar o perfil de uso dos computadores pelos professores em escolas públicas da cidade de Pombal e adjacências. Para isso, usamos a metodologia descrita em [Creswell 2013] para conduzir um survey cross-sectional. Este foi adotado por ser um método econômico de coleta de dados, fornecendo um tempo de retorno rápido em um ponto do tempo. Adicionalmente, usamos coleta de dados auto-administrada com questionários impressos, onde os próprios entrevistados respondiam às perguntas sem a orientação de entrevistadores e não havia uso de internet. Isto ocorreu porque nem todas as escolas dispunham de acesso à internet e nosso escopo envolvia várias cidades, o que trazia limitações econômicas e temporais à aplicação dos questionários.

Aplicamos dois tipos de questionários com respostas categóricas (sim/ não). O primeiro tipo compunha 16 questões e foi direcionado aos professores para identificar o conhecimento deles em informática, assim como seus comportamentos durante o uso dos computadores nas aulas (Figura 1). O segundo questionário (Figura 2) possui 4 questões e foi aplicado para os diretores com o objetivo de caracterizar a infraestrutura computacional das escolas públicas e a frequencia de uso do laboratórios de informática disponíveis nas escolas.

A população estudada consistiu de todos os professores da $13^{a}$ Gerência Regional de Ensino gerenciada pela Secretaria de Educação do Estado da Paraíba, englobando as cidades de Pombal (zona urbana e rural), Cajazeirinhas, São Bentinho, Lagoa, Condado, Paulista, Vista Serrana e São Domingos. O tamanho da população foi obtido através de informações dos diretores, resultando em 239 professores.

Para escolher a amostra, realizamos contatos telefônicos com os diretores dessas escolas. Toda as escolas pertencentes a esta Gerência Regional de Ensino foram convidadas, no entanto 6 de um total de 20 escolas não aceitaram colaborar. Mesmo assim, obtivemos participação de todas as cidades pretendidas. Depois de aceito o convite, enviamos questionários para cada diretor, que os aplicava com os professores. Como a participação no survey dependia da disponibilidade do participante, podemos classificar a amostra de 134 professores como de conveniência. Não conseguimos uma lista completa dos professores de todas as escolas, o que impossibilitou identificar os indivíduos da população e escolher uma amostra aleatória. Com isso, nossa amostra é multiestágio e 
1. Você possui computador em casa?

2. Você tem acesso à internet?

3. Você utiliza o computador para auxiliar suas aulas?

4. O computador que você tem acesso na escola é de fácil disponibilidade?

5. A frequência com que você trabalha com os alunos no laboratório de informática é alta?

6. Os alunos colaboram com as atividades desenvolvidas no laboratório de informática?

7. A participação dos professores em cursos e oficinas que auxiliem e orientem a utilização dos recursos computacionais seria importante?

8. Há disponibilidade sua para participar de cursos de capacitação?

9. Você tem dificuldade em usar o computador?

10. Você já participou de um curso de informática básica?

11. Você já redigiu provas ou textos na escola com uso do computador?

12. Você prepara slides para exibir conteúdos escolares utilizando ferramentas de apresentação eletrônica (Power Point, Slides, etc)?

13. Você tem conhecimento técnico dos computadores, como por exemplo problemas de configuração, teclado e acesso à internet?

14. Existe algum programa de inclusão digital na escola em que você trabalha?

15. Você já participou de algum curso de capacitação para utilizar a internet em sua escola?

16. Você acredita que a inclusão digital pode melhorar o seu desempenho docente e dos seus alunos?

Figura 1. Questionário para professores

17. A escola possui laboratório de Informática?

18. O laboratório de informática possui acesso à internet?

19. Existem funcionários alocados para o conserto dos computadores?

20. Os alunos têm acesso aos computadores na escola?

Figura 2. Questionário para diretores

sem estratificação. A quantidade de questionários enviados e respondidos em cada escola é mostrada na Tabela 1.

Como a amostra da população corresponde 56,07\% (maior que 10\%) da população, esta é considerada estatisticamente válida [Field et al. 2012]. De posse dos questionários, desprezamos aqueles que não tinham todas as perguntas respondidas, sendo este o nosso método de descarte. Com isso, rejeitamos 5 questionários, reduzindo nossa amostra para 129 questionários.

Os questionários foram elaborados especificamente para este survey. Para garantir a validade de conteúdo do mesmo, interpretamos as questões elaboradas e as relacionamos com as variáveis estatísticas que pretendíamos considerar. Entretanto, não fizemos testes de campo para melhorar o processo de validação por restrições de tempo. Já para garantir a confiabilidade dos dados, a compilação dos resultados foi manual e conferida por 3 
Tabela 1. Quantificação de questionários entregues por escolas

\begin{tabular}{|l|l|r|r|}
\hline Escola & Cidade & \# Entregues & \% Recebidos \\
\hline \hline EEEFM. Arruda Câmera & Pombal & 38 & $50,00 \%$ \\
\hline EEEF. João da Mata & Pombal & 34 & $35,29 \%$ \\
\hline EEEMP. Mons. Vicente Freitas & Pombal & 20 & $95,00 \%$ \\
\hline EEEF. Oito de Julho & Pombal & 13 & $53,85 \%$ \\
\hline EEEF. Amélia Mária da Luz & Pombal & 13 & $46,15 \%$ \\
\hline EEEF. Estrelo & Pombal (Zona Rural) & 2 & $100,00 \%$ \\
\hline EEEF. Pedra Branca & Pombal (Zona Rural) & 2 & $100,00 \%$ \\
\hline EEEF. M $^{\text {a Soledade Freitas }}$ & Cajazeirinhas & 14 & $64,29 \%$ \\
\hline EEEFM. Levi Olímpio Ferreira & São Bentinho & 18 & $66,67 \%$ \\
\hline EEEFM. Frei Bruno & Lagoa & 9 & $44,44 \%$ \\
\hline EEEF. Dr. José Queiroga & Condado & 17 & $52,94 \%$ \\
\hline EEEFM. Fa De Sá Cavalcante & Paulista & 19 & $42,11 \%$ \\
\hline EEEFM. Manoel Medeiros & Vista Serrana & 22 & $72,73 \%$ \\
\hline EEEFM. Cícero Severo Lopes & São Domingos & 18 & $50,00 \%$ \\
\hline Total & & 239 & $56,07 \%$ \\
\hline
\end{tabular}

pessoas, pois os questionários eram impressos.

O survey foi conduzido para responder às seguintes questões descritivas: (1) Como os professores são avaliados em conhecimentos de informática? (2) Qual o nível da infraestrutura computacional disponível para os professores? (3) Como os professores usam os computadores durante as aulas? Com isso, foram identificadas as variáveis independentes "nível de conhecimento dos professores em informática"e "infraestrutura de informática disponível", além da variável dependente "uso dos computadores pelos professores em sala de aula". Convencionamos que cada variável poderia assumir os valores alto e baixo. Para relacionar esses níveis às respostas das questões, utilizamos a escala Likert, atribuindo o valor 1 para a resposta "sim", 0 para a resposta "não"e intervalos de valores para cada categoria. A Tabela 2 mostra a relação entre as variáveis estatísticas e os itens dos questionários aplicados, assim como os assuntos abordados em cada grupo de questões.

Adicionalmente, pretendemos responder às seguintes questões de inferência: (4) O nível de conhecimento dos professores em informática é relacionado ao uso dos computadores durante as aulas? (5) A infraestrutura de informática oferecida pelas escolas afeta o uso dos computadores pelos professores durante as aulas? Como as três variáveis envolvidas são categóricas e pretendedemos isvestigar a associação entre duas variáveis estatísticas por questão, usamos o teste chi-quadrado com o auxílio do software estatístico R. Adicionalmente, usamos análise log-linear para investigar a associação entre as três variáveis ao mesmo tempo e $\alpha$ igua a 5\% para todas as análises.

\section{Resultados}

Para responder as questões descritivas, mostramos o perfil inicial de infraestrutura das escolas informada pelos diretores, perfazendo um total de 14 entrevistados. A questão 17 informou que 10 escolas possuem laboratório de informática. Também pudemos constatar que 9 laboratórios possuem acesso à internet (questão 18) e 3 escolas possuem fun- 
Tabela 2. Correspondência entre variáveis e questões

\begin{tabular}{|l|l|l|}
\hline Nome da variável & Pergunta de pesquisa & Item do survey \\
\hline \hline $\begin{array}{l}\text { Variável indepen- } \\
\text { tente 1: Nível de } \\
\text { conhecimento dos } \\
\text { professores em emão de pesquisa } \\
\text { informática }\end{array}$ & $\begin{array}{l}\text { Qescritiva 1: Como os } \\
\text { professores são avaliados } \\
\text { em conhecimentos de } \\
\text { informática? }\end{array}$ & $\begin{array}{l}\text { e 16 do questionário do ques- } \\
\text { tionário 1: Conceitos básicos, } \\
\text { dificuldades ao usar computa- } \\
\text { dores e experiência em suítes } \\
\text { de escritório. }\end{array}$ \\
\hline $\begin{array}{l}\text { Variável indepen- } \\
\text { tente 2: Infraestru- } \\
\text { tura de informática } \\
\text { disponível }\end{array}$ & $\begin{array}{l}\text { Questão de pesquisa des- } \\
\text { critiva 2: Qual o nível da } \\
\text { infraestrutura computacio- } \\
\text { nal disponível? }\end{array}$ & $\begin{array}{l}\text { Vide questões 1, 2, 4, 7, 8, 10, } \\
\text { a 4 do questionário 2: Dispo- } \\
\text { a do questionário 1 e 1 } \\
\text { nibilidade de computadores, } \\
\text { acesso à internet e cursos de } \\
\text { capacitação em informática. }\end{array}$ \\
\hline $\begin{array}{l}\text { Variável dependente } \\
\text { 1: Uso dos compu- } \\
\text { tadores pelos profes- } \\
\text { sores em sala de aula }\end{array}$ & $\begin{array}{l}\text { Questão de pesquisa des- } \\
\text { critiva 3: Como os profes- } \\
\text { sores usam os computado- } \\
\text { res durante suas aulas? }\end{array}$ & $\begin{array}{l}\text { Vide questões 3, 5 e 6: Levan- } \\
\text { tamento de dificuldades que } \\
\text { impedem o uso dos computa- } \\
\text { dores nas aulas. }\end{array}$ \\
\hline
\end{tabular}

cionários alocados para o conserto dos computadores (questão 19). Adicionalmente, 8 escolas permitem que os alunos tenham acesso ao laboratório de informática. $\mathrm{O}$ gráfico contendo as frequências das respostas deste questionário são mostradas na Figura 3.

O questionário aplicado aos professores teve 129 entrevistados. Os resultados de cada questão estão citados por ordem, a saber: 125 professores informaram que têm computador em casa, 129 professores possuem acesso à internet, 103 professores usam os computadores durante suas aulas e 103 informam que o computador ao qual eles têm acesso é de fácil disponibilidade. Seguindo para a questão 5, continuamos em ordem: 35 professores usam o laboratório de informática frequentemente em suas aulas, 98 professores afirmam que os alunos colaboram com as atividades desenvolvidas no laboratório de informática, 129 afirmam que a participação dos professores em cursos ou oficinas é importante e que há disponibilidade deles para cursos de capacitação (questões 7 e 8), 38 têm dificuldade de usar o computador e 96 respondentes já participaram de cursos de informática anteriormente. Na sequência, a questão 11 informa que 97 professores já redigiu provas ou textos usando o computador, 58 preparam slides para exibir conteúdos escolares, 44 afirmam ter conhecimento técnico em computadores, 29 informam que há programas de inclusão digital na escola, 30 professores informam ter passado por cursos de capacitação e 129 afirmaram que a inclusão digital pode melhorar o desempenho docente e discente. A Figura 4 mostra o gráfico contendo as respostas do questionário submetido aos professores.

Com isso, temos as seguintes respostas para as questões descritivas:

\section{(1) Como os professores são avaliados em conhecimentos de informática?}

Sabendo que 84 professores foram enquadrados com conhecimento alto, concluímos que o conhecimento alto excede o conhecimento baixo em 30,24\%. Apesar da 


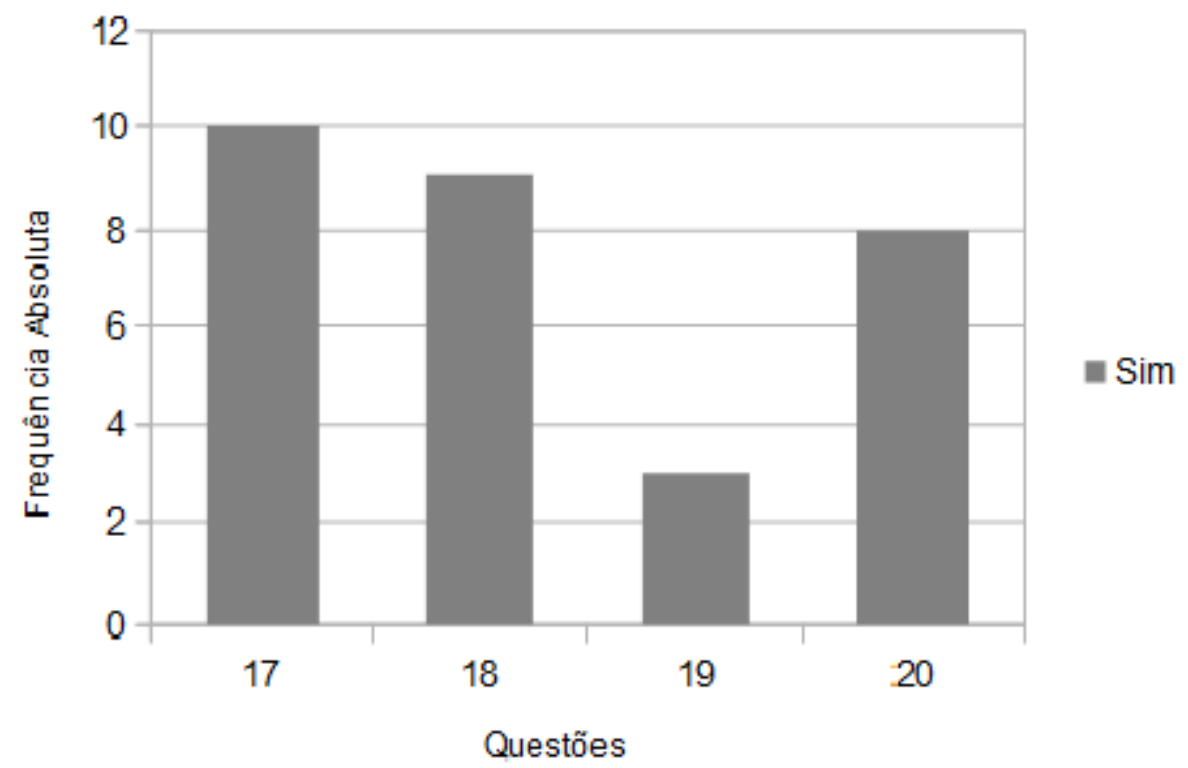

Figura 3. Respostas dos questionários dos diretores

maioria dos professores afirmar ter dificuldade em usar o computador e não possuir conhecimento técnico, mais da metade deles já usou suítes de escritório. Ademais, todos afirmam que a inclusão digital é capaz de melhorar o desempenho discente e docente.

\section{(2) Qual o nível da infraestrutura computacional disponível?}

As perguntas se referiam aos recursos computacionais disponíveis para o professor dentro e fora da escola. Verificamos que a infraestrutura alta é disponível para 86 professores, excedendo a baixa em 33,33\%. Observou-se que a maioria dos professores têm computador em casa com acesso à internet, além do acesso ao computador na escola ser de fácil disponibilidade. Ademais, a maioria afirma que não há capacitação disponível na área de informática e estes se mostraram disponíveis em participar dessa atividade. Em contrapartida, a maioria das escolas não possui funcionários alocados para o conserto dos computadores.

\section{(3) Como os professores usam os computadores durante as aulas?}

A maioria informou que usa os computadores durante as aulas. Adicionalmente, eles afirmaram que a maioria dos alunos colabora com as atividades desenvolvidas no laboratório, mas a minoria dos professores realiza aulas no laboratório frequentemente. Usando o software estatístico R, verificamos que existem 79 ocorrências para o uso baixo e 50 para uso alto, o que leva o uso do computadores a ser predominantemente baixo. Também observou-se que o uso dos computadores aumenta com a infraestrutura alta ou conhecimento alto.

Para responder às questões de inferência, usamos a análise log-linear que produziu um modelo final que não reteve todos os efeitos. A razão de verossimilhança deste modelo foi $\chi^{2}(0)=0 \mathrm{e} \mathrm{p}=1$. Isto indica que a mais alta ordem de interação (Uso dos computadores $x$ Infraestrutura x Conhecimento) não é estatisticamente significante para $\chi^{2}(1)$ $=0,06$ e $\mathrm{p}=0,79$. Para investigar esse efeito, testes qui-quadrado separados foram feitos 


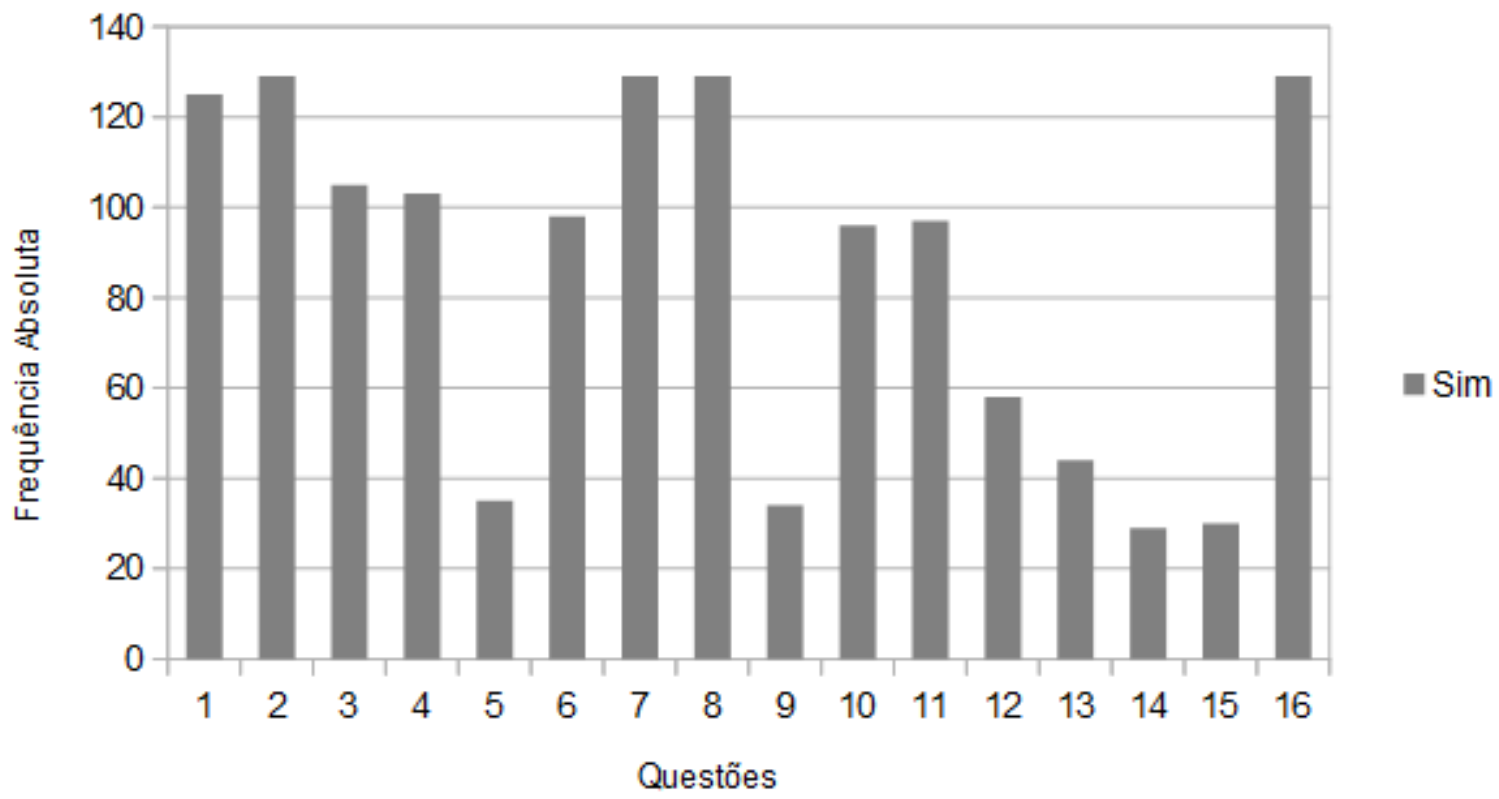

Figura 4. Respostas dos questionários dos professores

Tabela 3. Tabela de contingência para conhecimento alto

\begin{tabular}{|l|l|l|l|}
\hline & \multicolumn{3}{|l|}{ Uso dos computadores } \\
\hline Infraestrutura & Alto & Baixo & Total (linhas) \\
\hline Alta & 18 & 39 & $57(67,86 \%)$ \\
\hline Baixa & 12 & 15 & $27(32,14 \%)$ \\
\hline Total (colunas) & $30(35,71 \%)$ & $54(64,28 \%)$ & 84 \\
\hline
\end{tabular}

nas variáveis Infraestrutura e Uso dos computadores para Conhecimento e alto e baixo, assim como para as variáveis Conhecimento e Uso dos computadores para Infraestrutura alta e baixa. Com isso, as respostas das questões de inferência são:

(4) O nível de conhecimento dos professores em informática é relacionado ao uso dos computadores durante as aulas?

Para o conhecimento alto, não existiu associação significativa entre as variáveis Infraestrutura e Uso dos computadores, resultando em $\chi^{2}(1)=1,32$ e $p=0,25$. A razão de probabilidades indica que a chance do professor com conhecimento alto usar pouco os computadores é 1,72 vezes menor para a infraestrutura baixa em relação à alta. Além disso, a Tabela 3 mostra que a frequência de uso dos computadores baixa em sala de aula supera a alta em $28,57 \%$, ao passo que a infraestrutura alta supera a baixa em $35,72 \%$.

Para o conhecimento baixo, adquirimos $\chi^{2}(1)=0,31$ e $p=0,57$, o que revelou que as variáveis são independentes. A Tabela 4 mostra que o baixo uso dos computadores excede o alto uso em $11,12 \%$ e os níveis de infraestrutura diferem em $28,88 \%$. A razão de probabilidade indica que a chance do professor de conhecimento baixo usar pouco os computadores é 1,41 vezes menor para a infraestrutura baixa do que para a alta.

(5) A infraestrutura de informática oferecida pelas escolas afeta o uso dos computa- 
Tabela 4. Tabela de contingência para conhecimento baixo

\begin{tabular}{|l|l|l|l|}
\hline & \multicolumn{3}{|l|}{ Uso dos computadores } \\
\hline Infraestrutura & Alto & Baixo & Total (linhas) \\
\hline Alta & 12 & 17 & $29(64,44 \%)$ \\
\hline Baixa & 8 & 8 & $16(35,56 \%)$ \\
\hline Total (colunas) & $20(44,44 \%)$ & $25(55,56 \%)$ & 45 \\
\hline
\end{tabular}

\section{dores pelos professores durante as aulas?}

Para uma alta infraestrutura, o uso dos computadores e o conhecimento não apresentaram associação significativa. Com isso, $\chi^{2}(1)=0,81$ e $p=0,37$. Os resultados das razões de probabilidades informaram que a chance do professor com disponibilidade de infraestrutura alta usar pouco os computadores é 1,52 vezes menor para o professor com conhecimento baixo em relação ao alto. A Tabela 5 mostra que o baixo uso dos computadores excede o alto uso em $30,24 \%$.

Tabela 5. Tabela de contingência para infraestrutura alta

\begin{tabular}{|l|l|l|l|}
\hline & \multicolumn{3}{|l|}{ Uso dos computadores } \\
\hline Conhecimento & Alto & Baixo & Total (linhas) \\
\hline Alto & 18 & 39 & $57(66,28 \%)$ \\
\hline Baixo & 12 & 17 & $29(33,72 \%)$ \\
\hline Total (colunas) & $30(34,88 \%)$ & $56(65,12 \%)$ & 86 \\
\hline
\end{tabular}

Para a baixa infraestrutura, obtivemos $\chi^{2}(1)=0,12$ e $p=0,72$, o que mostra que as variáveis são independentes. A razão de probabilidades informa que a chance do professor submetido a uma baixa infraestrutura usar pouco os computadores é 1,24 vezes menor para o conhecimento baixo do que para o alto. A Tabela 6 mostra que o uso baixo dos computadores excede o alto em $6,98 \%$.

Tabela 6. Tabela de contingência para infraestrutura baixa

\begin{tabular}{|l|l|l|l|}
\hline & \multicolumn{3}{|l|}{ Uso dos computadores } \\
\hline Conhecimento & Alto & Baixo & Total (linhas) \\
\hline Alto & 12 & 15 & $27(62,79 \%)$ \\
\hline Baixo & 8 & 8 & $16(37,21 \%)$ \\
\hline Total (colunas) & $20(46,51 \%)$ & $23(53,49 \%)$ & 43 \\
\hline
\end{tabular}

\section{Conclusões}

O objetivo deste trabalho foi analisar como os computadores são usados pelos professores em escolas públicas de 6 cidades do Sertão Paraibano. Aplicamos 134 questionários para professores e 14 questionários para diretores com o objetivo de levantar dados sobre as variáveis estatísticas infra-estrutura, conhecimento em informática e uso dos computadores.

Verificamos que não existe associação significativa entre estas variáveis e que os professores têm um alto conhecimento em informática, com a maioria possuindo computador em casa e acesso à internet. Ademais, há um alta infraestrutura de informática 
disponível aos professores. Mesmo assim, a frequência de uso dos computadores é baixa, diminuindo com a alta infraestrutura ou o alto conhecimento.

Os trabalhos futuros incluem a aplicação de questionários em outras cidades com o objetivo de ampliar a caracterização dos professores des escolas públicas do Alto Sertão da Paraíba. Também pretendemos promover cursos de capacitação para os professores e medir o desempenho docente dos participantes após os cursos.

\section{Referências}

Andrade, M., Borges, F., França, G., and Ramos, L. (2012). Impactos iniciais na formação dos professores e gestores para o uso do laptop educacional no estado do Tocantins. Inter Science Place, 1:126-142.

Costa, A. L. M. and Almeida, F. J. D. (2012). Condições materiais e a eficácia da informática aplicada à educação : a culpa é do professor ? Workshop de Informática na Educaçao (WIE), XVII.

Creswell, J. W. (2013). Research design: Qualitative, quantitative, and mixed methods approaches. Sage publications, 4th edition.

Damasceno, A., Moreira, F., Santos, T., and Alvino, C. (2011). Inclusão digital na cidade de Pombal. In Workshop sobre Educação em Computação (WEI), pages 1689 - 1698.

Field, A., Miles, J., and Field, Z. (2012). Discovering statistics using R. Sage publications, 3rd edition.

Gomes, F. and Sá, R. (2012). Um Computador por Aluno em Araucária : investigando a prática dos professores. Workshop de Informática na Educaçao (WIE), XVIII.

Jeske, J. C., Silva, J., and Oliveira, R. (2009). Perfil da Informática na Educação nas Escolas Estaduais do Sudoeste Goiano. Workshop de Informática na Educaçao (WIE), pages 1831-1836.

Molin, I. S., Raabe, A., Educação, M., Aplicada, C. a., and Univali, I. (2012). Novas Tecnologias n Educação : Transformações da Prática Pedagógica no Discurso Do Professor. Workshop de Informática na Educaçao (WIE), XVIII.

Nascimento, K. A. S., Lima, M. S., Freire, R., and Filho, J. A. C. (2011). Um olhar sobre as atividades dos laboratórios de informática educativa das escolas municipais de Fortaleza. pages 1256 - 1263.

Odorico, E. K., Nunes, D. M., Moreira, A., and Oliveira, H. M. P. D. (2012). Análise do Não Uso do Laboratório de Informática nas Escolas Públicas e Estudo de Caso. Workshop de Informática na Educaçao (WIE), XVIII.

PNDU (2014). Programa das nações unidas para o desenvolvimento (pndu). Acessado em 16-07-2014.

Santos, D. A. d. N., Schlunzen, E. T. M., and Junior, K. S. (2011). Tecnologias educacionais na formação em serviço de professores: perspectivas para uma escola inclusiva. In Workshop de Informática na Educaçao (WIE), pages 1498 - 1506.

Silva, M. H. and Carvalho, L. M. T. L. (2011). A implementação do laboratório de informática na escola pública e o seu impacto no cotidiano escolar. Revista de Tecnologias (RETEC), 4(1):9-24. 